\title{
Self-selection of Dietary Threonine in the Rat and the Effect of Taste Stimuli on its Selection
}

\author{
Yukiko Yamamoto, ${ }^{*}$ Makoto Suzuki and Keiichiro Muramatsu \\ Laboratory of Food and Nutrition, Department of Agricultural Chemistry, \\ Faculty of Agriculture, Shizuoka University, \\ Shizuoka 422, Japan \\ Received February 12, 1985
}

\begin{abstract}
The possible regulation of dietary threonine intake and the effect of a palatable (sodium saccharin) or aversive (quinine sulfate) taste stimulus on the manner of threonine selection were investigated in rats using a self-selection feeding method. Weanling rats were offered the choice of two diets differing only in threonine content for 2 weeks. Both weight gain and food consumption in the rats offered the choice of diets were quite comparable to each other and were the same as those in rats fed one diet containing sufficient threonine. Threonine intake of the self-selecting rats ranged from 0.43 to $1.90 \%$ of the food consumed. The threonine concentrations in the plasma and brain of the self-selecting rats increased proportionally with the threonine intake. When rats were offered a choice of two diets containing various amounts of threonine with taste materials, i.e., sodium saccharin or quinine sulfate, neither the dietary threonine nor their growth were ever affected.

These results indicate clearly that rats have an ability to regulate threonine intake to meet their requirement for the L-amino acid, and the threonine selection is not influenced significantly by the dietary addition of palatable or aversive taste materials.
\end{abstract}

It has been clearly established that protein intake is definitely regulated in rats. ${ }^{1 \sim 4)}$ In relation to this phenomenon, it would be of interest to elucidate whether the intake of essential amino acids is also regulated. Halstead and Gallagher ${ }^{5)}$ observed that rats possessed the ability to discriminate between two solutions containing a complete amino acid mixture with or without threonine. Rogers and Harper ${ }^{6)}$ reported that rats fed a histidine imbalance diet drank more of a histidine solution in order to improve their diet. Kishi et al. $^{7)}$ showed that rats, fed an amino acid mixture diet lacking one essential amino acid, drank more of the single amino acid solution than water, and that the animals could select the amino acid to meet their requirement level. Previously, Muramatsu and co-workers ${ }^{8 \sim 10)}$ demonstrated that rats have an ability to regulate methionine, lysine or phenylalanine intake using a self-selection feeding method, and that the animals consume a diet in order to satisfy their requirement for the amino acid in question.

The present study was conducted to determine the dietary threonine intake using a self-selection technique, and the relationship between threonine consumption and its concentration in the plasma and brain. The effect of the addition of taste materials to diets containing different levels of threonine on the manner of selection was also investigated.

\section{MATERIALS AND METHODS}

Animals and diets. Male weanling rats of the Wistar strain*1 (28 days of age) were used. Rats were offered a $25 \%$ casein diet for 3 to 4 days before the experiments, then rats weighing 55 to $60 \mathrm{~g}$ were separated into groups ( $N=4$ for fixed feeding groups and $N=5$ for self-selection feeding groups). Each rat was individually housed in a suspended cage with a screen bottom $(25 \times 18 \times 18 \mathrm{~cm})$, and the animal room was maintained at $24 \pm 1^{\circ} \mathrm{C}$ with a

* Present address: Department of Education, Tokoha Gäkuen University, Shizuoka 420, Japan.

*1 Shizuoka Agricultural Cooperation Association for Laboratory Animals, Hamamatsu. 
Table I. Compositions of EXPerimental Diets

\begin{tabular}{|c|c|c|c|c|c|}
\hline Ingredient & $10 \mathrm{AA}-\mathrm{Th}$ & $10 \mathrm{AA} 0.25 \mathrm{Th}$ & $10 \mathrm{C} 0.16 \mathrm{Th}$ & $10 \mathrm{C} 1 \mathrm{Th}$ & $10 \mathrm{C} 2 \mathrm{Th}$ \\
\hline \multicolumn{6}{|c|}{$(\mathrm{g} / 100 \mathrm{~g})$} \\
\hline Casein & - & - & 10.0 & 10.0 & 10.0 \\
\hline Potato $\alpha$-starch & 76.15 & 76.15 & 74.98 & 74.14 & 73.14 \\
\hline Corn oil & 5.0 & 5.0 & 5.0 & 5.0 & 5.0 \\
\hline Salt mixture ${ }^{1}$ & 5.0 & 5.0 & 5.0 & 5.0 & 5.0 \\
\hline Vitamin mixture $^{1}$ & 1.0 & 1.0 & 1.0 & 1.0 & 1.0 \\
\hline Choline chloride & 0.1 & 0.1 & 0.1 & 0.1 & 0.1 \\
\hline L-Threonine & - & 0.25 & 0.16 & 1.0 & 2.0 \\
\hline L-Glutamic acid & 4.72 & 4.47 & 2.42 & 2.42 & 2.42 \\
\hline Amino acid mixture & $8.03^{2}$ & $8.03^{2}$ & $1.19^{3}$ & $1.19^{3}$ & $1.19^{3}$ \\
\hline
\end{tabular}

1 A. E. Harper, J. Nutr., 68, 405 (1959).

2 Contents of the essential amino acid mixture for the 10AA-Th and 10AA0.25Th diets corresponded to the essential amino acid contents according to NRC requirements (Arg- $\mathrm{HCl}, 0.72 ; \mathrm{His}, 0.3 ; \mathrm{Lys}-\mathrm{HCl}, 1.1 ; \mathrm{Phe}, 0.44$; Trp, 0.15; Met, 0.57; Ile, 0.55; Leu, 0.77; Val, 0.6), and the contents of nonessential amino acids simulated $10 \%$ casein (Tyr, 0.48; Cys, 0.03; Ser, 0.48; Asp, 0.50; Gly, 0.16; Ala, 0.24; Pro, 0.94).

3 The amino acid mixture for the $10 \mathrm{C} 0.16 \mathrm{Th}, 10 \mathrm{C} 1 \mathrm{Th}$ and $10 \mathrm{C} 2 \mathrm{Th}$ diets contained essential amino acids which are deficient compared to $\mathrm{NRC}$ requirements (Arg-HCl, 0.34; His, 0.07; Lys-HCl, 0.34; Trp, 0.04; Met, 0.32; Ile, 0.05; Val, 0.03).

$12 \mathrm{hr}$ cycle of light $(06: 00 \sim 18: 00 \mathrm{hr})$ and dark.

The compositions of experimental diets are given in Table I. The protein source of these diets was based on a $10 \%$ casein diet which was supplemented with some essential amino acids to simulate the essential amino acid pattern of NRC requirements. Test diets and water were supplied ad libitum for 2 weeks, and body weight and food intake were recorded each morning. Daily food consumption was measured on a dry matter basis with correction for spillage, and amounts of ingested threonine were calculated from the amounts of food consumed.

Fixed feeding experiment. Rats were offered a single diet containing various amounts of threonine; an amino acid mixture diet lacking L-threonine (10AA-Th), an amino acid mixture diet with $0.25 \%$ L-threonine (10AA0.25Th), and a $10 \%$ casein plus amino acid mixture diet supplemented with $0.16,1.0$ or $2.0 \%$ L-threonine $(10 \mathrm{C} 0.16 \mathrm{Th}$, $10 \mathrm{C} 1 \mathrm{Th}, 10 \mathrm{C} 2 \mathrm{Th})$.

Self-selection feeding experiment. Rats were given a choice between the 10AA-Th or 10AA0.25Th diet and the $10 \mathrm{C} 0.16 \mathrm{Th}, 10 \mathrm{C} 1 \mathrm{Th}$ or $10 \mathrm{C} 2 \mathrm{Th}$ diet, and a choice between the $10 \mathrm{C} 0.16 \mathrm{Th}$ diet and $10 \mathrm{C} 1 \mathrm{Th}$ or $10 \mathrm{C} 2 \mathrm{Th}$ diet. The 2 diet containers were kept in opposite corners of the cages and were changed daily to prevent effects due to positioning.

Effects of taste stimuli on threonine selection. Preference tests were carried out with the 10AA-Th and 10C0.16Th, or the 10AA0.25Th and 10C1Th diets with the addition of $0.35 \%$ sodium saccharin (10AA-ThS, 10AA0.25ThS) or $0.02 \%$ quinine sulfate (10C0.16ThQ, 10C1ThQ) which were shown to be taste stimuli for rats. ${ }^{11)}$

Threonine determination. At the end of the experimental period, rats were anesthetized with diethyl ether gas and blood was obtained with a heparinized tube by heart puncture. Plasma was prepared by centrifugation and homogenized with an equal volume of $6 \%$ sulfosalicilic acid (SSA). The brain was removed from the carcass as soon as possible after decapitation, and homogenized with 2 volumes of $6 \%$ SSA. The free threonine levels in both clear supernatants obtained from the plasma and brain were determined with an amino acid analyzer (Model 835 Hitachi Co., Japan).

\section{RESULTS}

The body weight gain, food consumption and threonine intake in rats offered diets according to the fixed-ratio or self-selection feeding method are shown in Table II. When rats were fed the single diets, the maximum growth was seen in the rats that consumed the $10 \mathrm{C} 0.16 \mathrm{Th}, 10 \mathrm{C} 1 \mathrm{Th}$ and $10 \mathrm{C} 2 \mathrm{Th}$ diets. The rats fed the 10AA0.25Th diet grew significantly less, and the rats fed the diet lacking threonine (10AA-Th) lost weight. Food consumption in these groups was not different, except that the value for the 10AA-Th group was significantly very low.

The body weight gain and food consumption in rats offered a choice of two diets 
Table II. The Effects of Fixed-ratio and Self-Selection Feeding Methods on Body Weight Gain, Food Consumption and Threonine Intake in RATs OfFered Diets Differing in Threonine Content

\begin{tabular}{|c|c|c|c|c|c|c|}
\hline & & & \multicolumn{3}{|c|}{ Food consumption } & \multirow{3}{*}{$\begin{array}{c}\text { Threonine } \\
\text { intake }\end{array}$} \\
\hline \multirow{2}{*}{\multicolumn{2}{|c|}{ Group }} & \multirow{2}{*}{$\begin{array}{c}\text { Body weight } \\
\text { gain }\end{array}$} & \multirow{2}{*}{ Total intake } & \multicolumn{2}{|c|}{ Food-preference } & \\
\hline & & & & (1) & (2) & \\
\hline & & & \multicolumn{3}{|c|}{ (g/2weeks) } & \\
\hline \multicolumn{7}{|l|}{ Fixed-feeding } \\
\hline 10AA-Th & & $-15.3 \pm 0.4^{\mathrm{a} 1}$ & $53.3 \pm 1.6^{\mathrm{a}}$ & & & 0.0 \\
\hline $10 \mathrm{AA} 0.25 \mathrm{Th}$ & & $23.5 \pm 1.3^{\mathrm{b}}$ & $134.2 \pm 2.9^{\mathrm{b}}$ & & & $0.34 \pm 0.01$ \\
\hline $10 \mathrm{C} 0.16 \mathrm{Th}$ & & $57.1 \pm 3.4^{\mathrm{cd}}$ & $146.2 \pm 5.1^{\mathrm{bc}}$ & & & $0.74 \pm 0.03$ \\
\hline $10 \mathrm{C} 1 \mathrm{Th}$ & & $53.8 \pm 2.2^{\mathrm{c}}$ & $141.3 \pm 2.9^{\mathrm{b}}$ & & & $1.90 \pm 0.04$ \\
\hline $10 \mathrm{C} 2 \mathrm{Th}$ & & $54.0 \pm 1.1^{\mathrm{c}}$ & $139.2 \pm 2.5^{\mathrm{b}}$ & & & $3.26 \pm 0.06$ \\
\hline \multicolumn{7}{|c|}{ Self-selection feeding } \\
\hline (1)10AA-Th & $v s .(2) 10 \mathrm{C} 0.16 \mathrm{Th}$ & $59.3 \pm 1.7^{\mathrm{d}}$ & $157.1 \pm 2.6^{\mathrm{c}}$ & $21.2 \pm 2.0$ & $135.9 \pm 1.6$ & $0.69 \pm 0.01$ \\
\hline (1) $10 \mathrm{AA}-\mathrm{Th}$ & vs. (2) $10 \mathrm{C} 1 \mathrm{Th}$ & $59.3 \pm 1.1^{\mathrm{d}}$ & $151.0 \pm 6.8^{b c}$ & $35.7 \pm 5.3$ & $115.3 \pm 4.3$ & $1.55 \pm 0.06$ \\
\hline (1) $10 \mathrm{AA}-\mathrm{Th}$ & vs. (2) $10 \mathrm{C} 2 \mathrm{Th}$ & $55.7 \pm 1.0^{\mathrm{cd}}$ & $144.3 \pm 2.3^{\mathrm{b}}$ & $26.8 \pm 7.2$ & $117.5 \pm 5.3$ & $2.75 \pm 0.12$ \\
\hline (1) $10 \mathrm{AA} 0.25 \mathrm{Th}$ & vs. (2) $10 \mathrm{C} 0.16 \mathrm{Th}$ & $60.4 \pm 1.4^{\mathrm{d}}$ & $155.9 \pm 3.7^{\mathrm{c}}$ & $44.6 \pm 3.0$ & $111.3 \pm 2.1$ & $0.67 \pm 0.01$ \\
\hline (1)10AA0.25Th & vs. (2) $10 \mathrm{C} 1 \mathrm{Th}$ & $58.2 \pm 0.8^{\mathrm{cd}}$ & $150.5 \pm 16.0^{\mathrm{bc}}$ & $52.0 \pm 12.0$ & $98.5 \pm 10.6$ & $1.45 \pm 0.11$ \\
\hline (1)10AA0.25Th & vs. (2) $10 \mathrm{C} 2 \mathrm{Th}$ & $56.4 \pm 1.1^{\mathrm{cd}}$ & $140.2 \pm 2.2^{\mathrm{b}}$ & $32.7 \pm 6.0$ & $107.6 \pm 4.9$ & $2.60 \pm 0.10$ \\
\hline (1) $10 \mathrm{C} 0.16 \mathrm{Th}$ & vs. (2) $10 \mathrm{C} 1 \mathrm{Th}$ & $58.0 \pm 1.2^{\mathrm{cd}}$ & $147.0 \pm 6.4^{\mathrm{bc}}$ & $75.4 \pm 4.8$ & $71.6 \pm 4.3$ & $1.34 \pm 0.04$ \\
\hline (1) $10 \mathrm{~A} 0.16 \mathrm{Th}$ & vs. (2) $10 \mathrm{C} 2 \mathrm{Th}$ & $56.8 \pm 1.0^{\mathrm{cd}}$ & $145.0 \pm 3.5^{\mathrm{b}}$ & $81.2 \pm 5.1$ & $64.7 \pm 4.9$ & $1.92 \pm 0.09$ \\
\hline
\end{tabular}

1 Mean $\pm \operatorname{SEM}$ ( $n=4$ for fixed feeding rats, $n=5$ for self-selection feeding rats). Values in the same column without common superscripts are significantly different $(p<0.05)$.

according to the self-selection feeding method were not significantly different from each other and were the same as those observed in the rats fed the single diets, $10 \mathrm{C} 0.16 \mathrm{Th}, 10 \mathrm{C} 1 \mathrm{Th}$ and $10 \mathrm{C} 2 \mathrm{Th}$.

The rats offered the choice of the 10AA-Th and one of the 10C0.16Th, 10C1Th and $10 \mathrm{C} 2 \mathrm{Th}$ diets, ate more of the latter than the 10AA-Th diet. When rats were offered the choice of the 10AA0.25Th diet and one of the $10 \mathrm{C} 0.16 \mathrm{Th}, 10 \mathrm{C} 1 \mathrm{Th}$ and $10 \mathrm{C} 2 \mathrm{Th}$ diets, they consumed the 10AA0.25Th one predominantly. When rats were offered a choice of the $10 \mathrm{C} 0.16 \mathrm{Th}$ and $10 \mathrm{C} 1 \mathrm{Th}$ diets or the $10 \mathrm{C} 0.16 \mathrm{Th}$ and $10 \mathrm{C} 2 \mathrm{Th}$ diets, the dietary threonine intake was quite comparable to each other.

Figure 1 shows the relationship between the threonine intake and the body weight gain in rats fed diets according to the fixed-ratio and self-selection feeding methods. Threonine intake of self-selecting rats ranged from 0.43 to

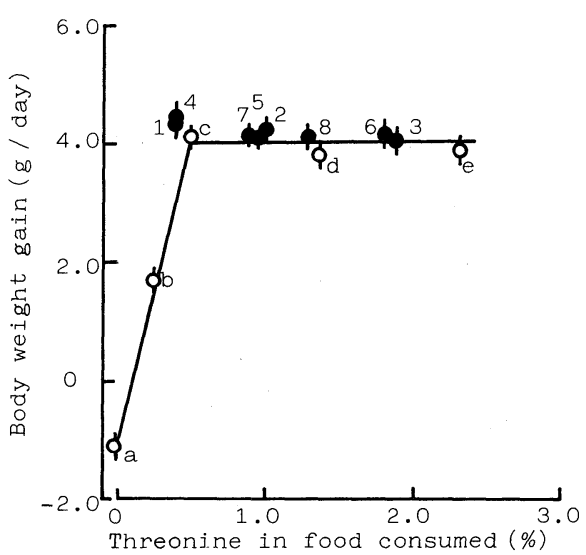

FIG. 1. The Effects of Fixed-ratio and Self-selection Feeding Methods on Threonine Intake and Body Weight Gain of Rats.

Symbols used in the graph are: a, 10AA-Th; b, 10AA0.25Th; c, 10C0.16Th; d, 10ClTh; e, 10C2Th; 1 , 10AA-Th vs. 10C0.16Th; 2, 10AA-Th vs. 10CITh; 3, 10AATh vs. 10C2Th; 4, 10AA0.25Th vs. 10C0.16Th; 5, 10AA0.25Th vs. 10C1Th; 6, 10AA0.25Th vs. 10C2Th; 7, 10C0.16Th vs. 10C1Th; 8, 10C0.16Th vs. 10C2Th. 


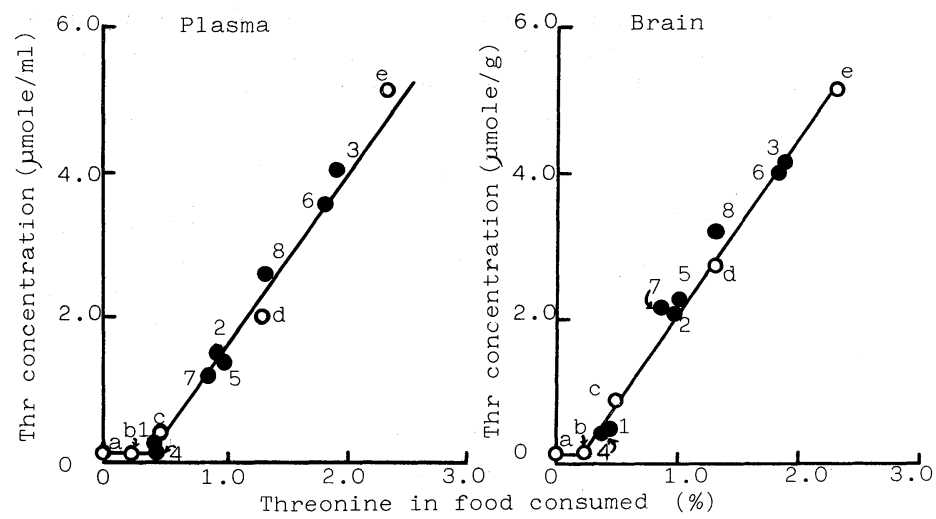

FIG. 2. Relationship between Threonine in Food Consumed and the Threonine Concentrations in Plasma and Brain.

Symbols in the graph are the same as in the footnote to Fig. 1.

Table III. Effect of Palatable and Aversive Tastes on Threonine Selection

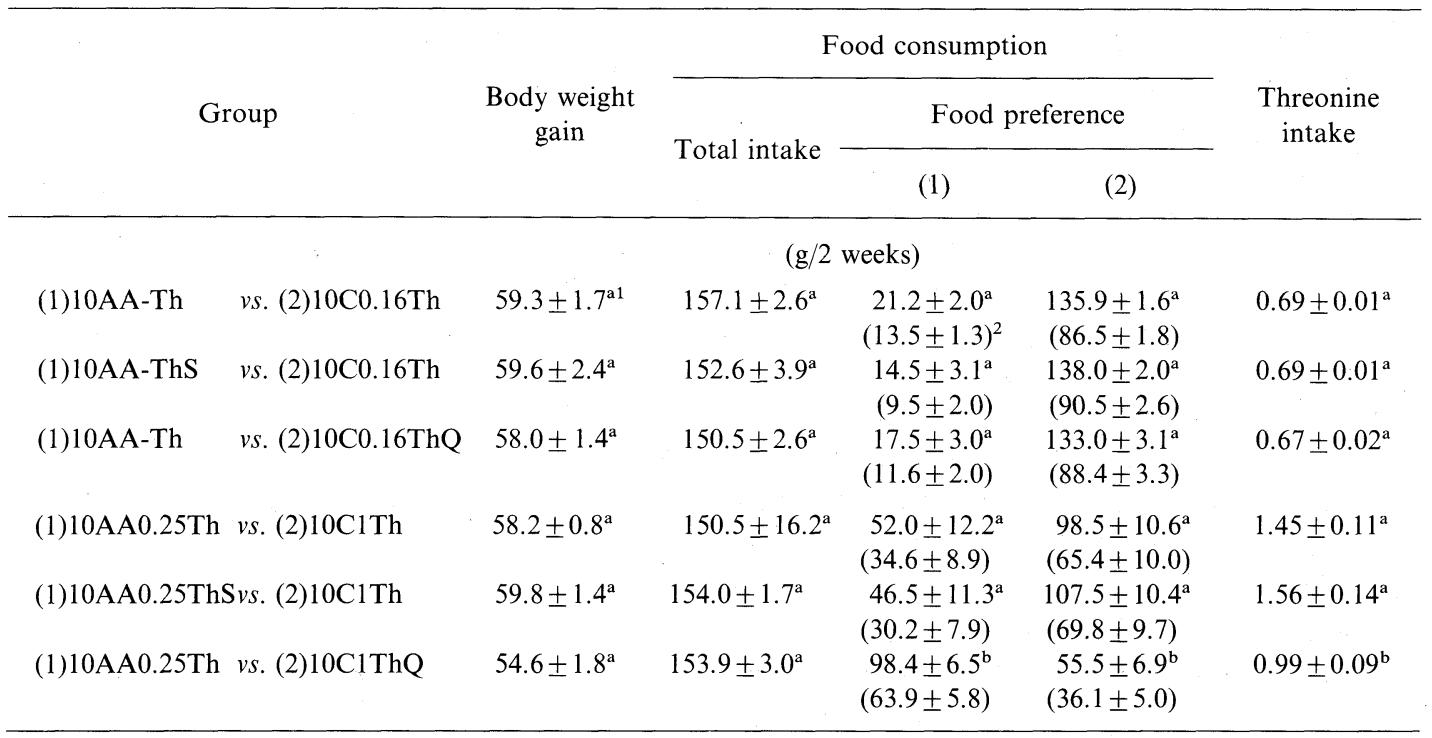

1 Mean \pm SEM. Values in the same column without common superscripts are significantly different $(p<0.05)$.

2 Percentages of food selected during the two week experiment.

$1.90 \%$ of the food consumed.

The relationship between the amount of threonine in food consumed and the threonine concentration in plasma and brain is shown in Fig. 2. Threonine intake is expressed as a percentage of the food consumed during the experimental period. The threonine concentration in plasma of rats fed the 10AA-Th or 10AA0.25Th diet was low, and it was elevated remarkably in rats fed the $10 \mathrm{C} 0.16 \mathrm{Th}, 10 \mathrm{C} 1 \mathrm{Th}$ or $10 \mathrm{C} 2 \mathrm{Th}$ diet. The threonine concentration in plasma of self-selecting rats also increased proportionally as the threonine intake increased. The threonine concentration in brain of rats fed diets according to the fixed feeding or self-selection feeding method showed the same trend as the threonine concentration in plasma.

Table III shows the effect of palatable and aversive taste materials on threonine selection. When rats were offered the choice of the 10AA-Th and 10C0.16Th diets, the 10C0.16Th 
diet was mainly consumed. The addition of taste materials, sodium saccharin to the 10AATh diet (10AA-ThS) or the addition of quinine sulfate to the $10 \mathrm{C} 0.16 \mathrm{Th}$ diet $(10 \mathrm{C} 0.16 \mathrm{ThQ})$, failed to alter the preference of the rats for the diet containing an adequate amount of threonine $(10 \mathrm{C} 0.16 \mathrm{Th})$. When rats were offered the choice of the 10AA0.25Th and 10C1Th diets, they consumed more of the 10C1Th diet than the 10AA0.25Th diet. The addition of sodium saccharin to the 10AA0.25Th diet (10AA0.25ThS) failed to alter their preference for this diet, but the selection ratio for the $10 \mathrm{C} 1 \mathrm{Th}$ diet was markedly decreased by the addition of quinine sulfate to the diet (10C1ThQ).

\section{DISCUSSION}

The results of the present experiments demonstrate that rats have an ability to regulate dietary threonine intake when offered a choice of two diets varying in threonine content. Rats showed threonine intakes ranging from 0.43 to $1.90 \%$ of the food consumed. The lowest threonine intake $(0.43 \%)$ of the self-selecting rats which attained maximal growth was in close agreement with the threonine requirement values of rats reported by McLaughlan and Illman $(0.42 \%)^{12)}$ and Pick and Meade $(0.43 \%),{ }^{13)}$ but was somewhat lower than the values reported by Rama Rao et al. $(0.51 \%)^{14)}$ and Kang-Lee and Harper $(0.50 \%){ }^{15)}$

The highest threonine intake $(1.90 \%)$ of the self-selecting rats was about 4 times that of the minimum requirement. The results suggest that rats are able to select threonine beyond their physiological need as in the case of methionine ${ }^{8)}$ lysine ${ }^{8)}$ and phenylalanine. ${ }^{10)}$

The relationship between the amount of threonine ingested and the free threonine concentration in plasma of rats has been studied by several investigators. Kang-Lee and Harper ${ }^{15)}$ observed that the threonine concentration in the plasma is very low when the dietary content of threonine is lower than the threonine requirement, and then it increases sharply as the dietary threonine content is increased. On the other hand, McLaughlan and Illman ${ }^{12)}$ reported that the plasma threonine concentration increased linearly as the dietary threonine content increased.

Our results indicated that in the case of single diets containing various levels of threonine offered to rats, the threonine concentrations in plasma and brain were low when the dietary threonine content was lower than half the threonine requirement level, and that the threonine concentration in the plasma and brain increased proportionally as the consumed amount of threonine increased. The threonine concentration in plasma and brain of rats given the choice of two diets according to the self-selection feeding method also changed proportionally with the consumed amount of threonine. These facts are not in agreement with our previous result in an experiment on phenylalanine selection that the phenylalanine and tyrosine concentrations in plasma and brain of rats that had consumed sufficient amounts of phenylalanine were maintained at normal levels. ${ }^{10)}$ Whether the concentration of threonine in plasma or tissues is important for the regulation of the amino acid intake has not been determined clearly, but it may influence directly or indirectly the regulation of essential L-amino acid intake.

The effect of taste on the selection of single essential amino acids has not been clarified. The present results (Table III) showed that the selection pattern for threonine was altered by an aversive taste such as that of quinine sulfate, but that rats consumed threonine to satisfy their requirement under these experimental conditions.

The present study demonstrated that rats have an ability to regulate dietary threonine intake to allow maximum growth, and taste stimuli have only a little effect on the regulation of threonine selection dietically.

\section{REFERENCES}

1) B. Musten, D. Peace and G. H. Anderson, J. Nutr., 104, 563 (1974).

2) D. V. M. Ashley and G. H. Anderson, J. Nutr., 105, 
1405 (1975).

3) G. H. Anderson, Adv. Nutr. Res., 1, 145 (1977).

4) K. Muramatsu and H. Kanematsu, Rep. Res. Commun. Essen. Amino Acids (Japan), 96, 32 (1982).

5) W. C. Halstead and B. B. Gallagher, J. Comp. Physiol. Psychol., 55, 107 (1962).

6) Q. R. Rogers and A. E. Harper, J. Comp. Physiol. Psychol., 72, 66 (1970).

7) K. Kishi, F. Shizuka and G. Inoue, Rep. Res. Commun. Essen Amino Acids (Japan), 96, 37 (1982).

8) K. Muramatsu and M. Ishida, J. Nutr. Sci. Vitaminol., 28, 149 (1982).

9) K. Muramatsu and M. Ohya, Agric. Biol. Chem., 46,
1647 (1982).

10) Y. Yamamoto, K. Makita and K. Muramatsu, $J$. Nutr. Sci. Vitaminol., 30, 273 (1984).

11) T. Yamamoto and Y. Kawamura, Physiol. Behav., 9, 559 (1972).

12) J. M. McLaughlan and W. I. Illman, J. Nutr., 93, 21 (1969).

13) R. I. Pick and R. J. Meade, J. Nutr., 101, 1241 (1971).

14) P. B. Rama Rao, V. C. Metta and B. C. Johnson, J. Nutr., 69, 387 (1959).

15) Y. Ae Kang-Lee and A. E. Harper, J. Nutr., 108, 163 (1978). 